\title{
ESTUDO EXPERIMENTAL SOBRE A POSSIBILIDADE DE PREVENÇÃO DA MALÁRIA PÓS-TRANSFUSIONAL, ATRAVÉS DO USO DA VIOLETA DE GENCIANA
}

\author{
Vicente Amato Neto* \\ Eunice José de Sant'Ana* \\ Pedro Luiz Silva Pinto* \\ Antonio Augusto Baillot Moreira* \\ Maria Irma Seixas Duarte*** \\ Rubens Campos**
}

\begin{abstract}
AMATO NETO, V. et al. Estudo experimental sobre a possibilidade de prevenção da malária pós-transfusional, através do uso da violeta de genciana. Rev. Saúde públ., S. Paulo, 21:497-500, 1987.

RESUMO: Levando em conta a comprovada ação preventiva da violeta de genciana quanto à transmissão da doença de Chagas, por transfusão de sangue e, também, possível idêntica eficácia a respeito da toxoplasmose, foi empreendida investigação para verificar se esse corante tem, da mesma forma, a capacidade de evitar a malária decorrente de hemoterapia. Foi investigada a infecção de camundongos pelo Plasmodium berghei. Usando parasitemia, mortalidade e alterações histopatológicas como parâmetros, verificou-se que a violenta de genciana, adicionada ao sangue, nas concentrações de $1 / 1.000$ e $1 / 4.000$, opõe-se efetivamente à ação infectante do protozoário, após permanência em geladeira $\left(4^{\circ} \mathrm{C}\right)$ durante 24 horas. Conclui-se que se abre nova perspectiva quanto à profilaxia da malária induzida, em serviços de hemoterapia.
\end{abstract}

UNITERMOS: Malária, prevenção e controle. Violeta de genciana, farmacodinâmica. Plasmodium berghei, efeitos de drogas. Camundongos, parasitologia. Transfusão de sangue, efeitos adversos.

\section{INTRODUÇÃO}

Várias infecções são transmissíveis por meio da transfusão de sangue. Entre elas, algumas, mais comumente, têm merecido considerações e preocupações, como a doença de Chagas, as hepatites por vírus $B$ e não $A$-não $B$, a malária, a sífilis e a Síndrome da Imunodeficiência Adquirida (AIDS).

Diante dessa realidade, torna-se imperioso adotar medidas preventivas, a fim de permitir conveniente proteção dos receptores benefiáveis da hemoterapia.

Para evitar a infecção transfusional, diferentes condutas são recomendadas e incluem providências que variam com $\circ$ atendimento de pessoas em regióes onde há endemicidade ou não. Elas levam em conta informações sobre malária anterior ou exposição à parasitose, execução de prova sorológica de imunofluores- cência indireta e, até mesmo, tratamento específico de doador e receptor. É lógico, entretanto, cogitar de aproveitamento do sangue, sempre que necessário e possível, respeitando o valor que ele encerra.

A violeta de genciana, conforme está categoricamente demonstrado, evita a veiculação transfusional da infecção causada pelo Trypanosoma cruzi, sem determinar inconvenientes distúrbios nos enfermos tratados através de sangue ao qual ela foi adicionada $a^{1,2,3,4,6}$. Convém ainda aduzir que esse corante, experimentalmente, em camundongos, revelou-se apto a coibir a aquisição da toxoplasmose por hemoterapia ${ }^{5}$. Diante dessa dupla capacidade, sentimo-nos estimulados a verificar se 0 agente profilático em tela pode opor-se à idêntica propagação da malária, também importante no contexto dos percalços atribuíveis ao uso de sangue e derivados como recursos úteis na

* Laboratório de Investigação Médica-Parasitologia do Hospital das Clínicas da Faculdade de Medicina da Universidade de São Paulo - Av. Dr. Arnaldo, 455 - 01246 - São Paulo, SP - Brasil.

* Departamento de Patologia da Faculdade de Medicina da Universidade de São Paulo - Av. Dr. Arnaldo, 455 - 01246 - São Paulo, SP - Brasil. 
prática médica cotidiana. E evidente que múltipla atividade de uma mesma providência condiciona desejáveis benefícios operacionais, materiais e assistenciais.

\section{MATERIAL E METODOS}

O procedimento estipulado baseou-se na infecção de camundongos (Balb-C) pelo Plasmodium berghei. Empregamos animais fêmeas, pesando entre 25 a $30 \mathrm{~g}$ e procedentes do Biotério da Faculdade de Medicina da Universidade de São Paulo.

Inoculamos, pela via intraperitoneal, sangue de camundongos, com anticoagulante ("Liquemine, Roche") e contendo o hematozoário; completamos com solução fisiológica estéril o volume de $0,5 \mathrm{ml}$ injetado. Compusemos os sete grupos adiante especificados, por vezes tendo havido adição da violeta de genciana, sempre observando as recomendações estabelecidas para Serviços de Hemoterapia e as metodologias adotadas nas investigações experimentais anteriormente publicadas, atinentes à profilaxia da doença de Chagas e da toxoplasmose $e^{1,2,3,4,5,6}$.

Grupo I: 13 animais; inoculação de sangue com aproximadamente $5 \times 10^{5}$ plasmódios e violeta de genciana a 1/1.000; conservação em geladeira, à temperatura de $4^{\circ} \mathrm{C}$, durante $24 \mathrm{~h}$.

Grupo II: 13 animais; inoculação de sangue com aproximadamente $5 \times 10^{5}$ plasmódios e violeta de genciana a 1/4.000; conservação em geladeira, à temperatura de $4^{\circ} \mathrm{C}$, durante $24 \mathrm{~h}$.

Grupo III: dez animais; inoculação de sangue com aproximadamente $5 \times 10^{5}$ plasmódios; conservação em geladeira, à temperatura de $4^{\circ} \mathrm{C}$, durante $24 \mathrm{~h}$.

Grupo IV: nove animais; inoculação de sangue com aproximadamente $5 \times 10^{5}$ plasmódios; sem violeta de genciana e conservação em geladeira.

Grupo V: cinco animais; inoculação de sangue sem plasmódios e com violeta de genciana a 1/1.000; conservação em geladeira, à temperatura de $4^{\circ} \mathrm{C}$, durante $24 \mathrm{~h}$.

Grupo VI: quatro animais; inoculação de sangue sem plasmódios e com violeta de genciana a 1/4.000; conservação em geladeira, à temperatura de $4^{\circ} \mathrm{C}$, durante $24 \mathrm{~h}$.

Grupo VII: cinco animais; inoculação de sangue sem plasmódios e violeta de genciana; conservação em geladeira, à temperatura de $4^{\circ} \mathrm{C}$, durante $24 \mathrm{~h}$.

A cepa de $P$. berghei da qual valemo-nos no estudo é a mantida no Laboratório de Investigação Médica-Parasitologia do Hospital das Clínicas da Faculdade de Medicina da Universidade de São Paulo.

A violeta de genciana foi-nos fornecida pela Divisão de Farmácia do Hospital das Clínicas (procedência alemã; adquirida da firma "Labormax"; violeta de genciana, $0,5 \mathrm{~g}$ - solução de glicose a $5 \%$, em água destilada q.s.p. $100 \mathrm{ml}$ ).

Decorridos 45 dias, matamos os camundongos remanescentes, dos diversos grupos. Os III e IV ficaram subdivididos em dois lotes, com cinco e quatro animais, respectivamente, para permitir sacrifício dos componentes com parasitemia de mais ou menos $10 \%$ ou observação até a morte e feitura da avaliação histopatológica.

Para avaliar o desempenho do corante estabelecemos os seguintes parâmetros: determinação da parasitemia sanguínea, em dias alternados, após coloração pelo método de Giemsa; registro da mortalidade; exame histopatológico de fragmentos de cérebro, fígado e pulmão, depois de processamento pela técnica da hematoxilina-eosina.

\section{RESULTADOS}

As parasitemias afiguraram-se crescentes nos animais que formavam os Grupos III e IV e chegaram a mais ou menos $10 \%$ oito dias depois da inoculação, quando sacrificamos os já mencionados; nos demais, comprovamos aumentos progressivos até a morte. Em clara contraposição, não existiram naqueles dos Grupos I e II.

Nas Tabelas 1 e 2 estão apresentadas nossas verificaçōes fundamentais acerca da mortalidade e das alterações histopatológicas.

$O$ que se passou quanto aos Grupos III e IV, ou seja, morte de todos os camundongos entre o $15 .^{\circ}$ e $\circ 28 .^{\circ}$ dias posteriores à infecção, deixa patente diferentes comportamentos, em confronto com os outros.

Também quando apreciadas as alterações histopatológicas, percebemos importantes diversidades, em termos de intensidade e frequiência, estando novamente implicados os roedores dos Grupos III e IV.

E imperioso esclarecer que nas condições, não totalmente adequadas em que trabalhamos, é esperado o óbito de animais, sem nexo com a experimentação, com a ocorrência de certos erros nas análises praticadas. Deixamos de examinar poucos camundongos que morreram, por não estarem eles em condição apropriada.

Anormalidades como Hiperplasia retículo-endotelial, infiltrado mononuclear portal ou 
TABELA 1

óbitos nos sete grupos estudados, distribuídos conforme a sobrevida em dias, e mortalidades observadas no final do estudo.

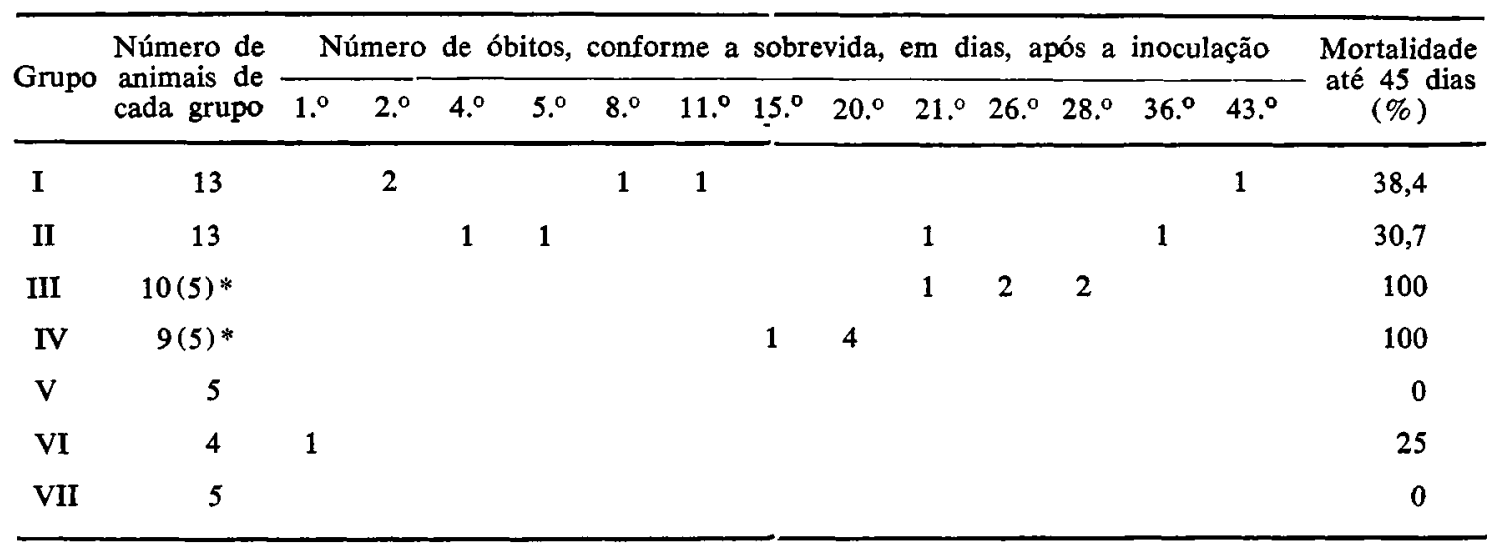

* Mantidos somente cinco para observação da mortalidade espontânea; os demais foram sacrificados, para avaliação histopatológica.

TABELA 2

Alterações histopatológicas observadas em fígado, pulmões e cérebro, nos sete grupos estudados.

\begin{tabular}{|c|c|c|c|c|c|c|c|}
\hline \multirow{2}{*}{ Alterações encontradas } & \multicolumn{7}{|c|}{ Grupos } \\
\hline & I & II & III & IV & $\mathbf{V}$ & VI & VII \\
\hline
\end{tabular}

Fígado

Hiperplasia retículo-endo-

$\begin{array}{llllll}\text { telial } & (+) 80 & (+) 100 & (+++) 80 & (++) 100 & (+) 20\end{array}$

Infiltrado mononuclear portal

Esteatose em hepatócitos

$$
\begin{array}{rrrr}
(++) 5 & (+) 50 & (++) 80 & (++) 100 \\
(+) 5 & & (+) 5 & \\
(+) 5 & (+) 5 & & (+) 50 \\
(+) 20 & (++) 80 & (+++) 100 & (+) 100 \\
& (+) 5 & (+++) 80 & (++) 5 \\
(+) 5 & (+) 5 & (+++) 80 & (+++) 100
\end{array}
$$

Necrose de hepatócitos

Infiltrado mononuclear intralobular

Pigmento malárico

Pulmões

Infiltrado mononuclear em brônquios

$$
(+) 5
$$

Infiltrado polimorfonuclear em brônquios

Pigmento malárico

Edema de septos

Infiltrado mononuclear em septos

$$
\begin{aligned}
& (+++) 20 \quad(+++) 20 \\
& (++) 20 \\
& (+) 50 \quad(++) 50 \quad(++) 50
\end{aligned}
$$

Luzes alveolares

\section{Cérebro}

$(+),(++)$ ou $(+++)$ : intensidade das alterações; os números correspondem, aproximadamente, a porcentagens, em relação aos animais examinados. 
intralobular, esteatose em hepatócitos e até outras, existentes moderadamente no fígado, podem ter decorrido de elementos inoculados, tais como sangue e parasitas. Até o encontro de pequena quantidade de pigmento malárico, é explicável dessa forma, acreditamos.

\section{DISCUSSÃO}

As parasitemias deixaram patente a eficácia da violeta de genciana, pois nos animais dos Grupos I e II mantiveram-se sistematicamente ausentes, em evidente contraste com o verificado nos dos Grupos III e IV, que a tinham até a morte. $O$ número de hematozoários aumentou progressivamente no sangue dos camundongos dos Grupos III e IV e, no oitavo dia pós-inoculação, atingiu cerca de $10 \%$; aí, sacrificamos cinco e, nos demais, a parasitemia foi aumentando, com subseqüente óbito espontâneo.

Quando consideramos a mortalidade percebemos como fato mais marcante a ocorrência desse evento, sem que tenha havido sacrifício intencional, em $100 \%$ dos animais, na fase que se situou entre 15 e 28 dias após a contaminação com o protozoário. $\mathrm{O}$ que houve nos Grupos V, VI e VII, sem a participação do $\boldsymbol{P}$. berghei, patenteia as ações protetoras da violeta de genciana e infectante do hematozoário, apuradas nos Grupos I, II, III e IV.

Valorizados os três parâmetros básicos que escolhemos, constituídos por parasitemia, mortalidade e deduçōes histopatológicas, assim como a estrutura global da pesquisa que convencionamos, surge como dedução viável a comprovação de que a violeta de genciana adicionada ao sangue, nas concentraçōes de $1 / 1.000$ e $1 / 4.000$, após permanência em geladeira $\left(4^{\circ} \mathrm{C}\right)$ durante $24 \mathrm{~h}$, opõe-se à infecção experimental de camundongos pelo $P$. berghei. Interpretando o que houve nos grupos organizados, apuramos que esse posicionamento é judicioso, abrindo perspectivas com sentido prático, referente à proposição de novos estudos, tendentes a procurar saber se o corante, de fato, pode ser útil em Serviços de Hemoterapia, prevenindo a malária humana pós-transfusional.

AMATO NETO, V. et al. [Experimental assay of the possible use of gentian violet in the prevention of post-transfusion malaria]. Rev. Saúde públ., S. Paulo, 21:497-500, 1987.

ABSTRACT: Considering that gentian violet is effective in the prevention of transfusion-acquired Chagas' disease and possibly toxoplasmosis, it is decided to carry out an experimental assay on the acitvity of this dye in the prevention of post-transfusion malaria. Mice infected with Plasmodium berghei were studied with regard to parasitemia, mortality and histopathologic changes. Gentian violet added to blood in $1 / 1.000$ and $1 / 4.000$ concentrations turned out to be effective in abolishing infectivity after storage for 24 hours at $4^{\circ} \mathrm{C}$. Thus is opened up a new prospect in the prophylaxis of post-transfusion malaria.

UNITERMS: Malaria, prevention and control. Gentian violet, pharmacodynamics. Plasmodium berghei, drug effects. Mice, parasitology. Blood transfusion, adverse effects.

\section{REFERÊNCIAS BIBLIOGRĀFICAS}

1. NUSSENZWEIG, V.; AMATO NETO, V.; MELLONE, $O$. Novos dados sobre o emprego da violeta de genciana na profilaxia da transmissão da doença de Chagas por transfusão de sangue. Hospital, Rio de Janeiro, 55:183-7, 1959.

2. NUSSENZWEIG, V.; BIANCALANA, A.; AMATO NETO, V.; SONNTAG, R.; FREITAS, J. L. P.; KLOETZEL, J. Ação da violeta de genciana sobre o $T$. cruzi "in vitro": sua importância na esterilização do sangue destinado à transfusão. [Nota prévia]. Rev. paul. Med., 42:57-8, 1953.

3. NUSSENZWEIG, V.; NUSSENZWEIG, R. S.; FREITAS, J. L. P.; AMATO NETO, V.; BIANCALANA, A.; KLOETZEL, J. Ação de agentes físicos e químicos sobre o Trypanosoma cruzi "in vitro". Hospital, Rio de Janeiro, 45:589-99, 1954.

4. NUSSENZWEIG, V.; SONNTAG, R.; BIANCALANA, A.; FREITAS, J. L. P.; AMATO NETO, V.; KLOETZEL, J. Ação de corantes tri-fenil-metânicos sobre o Trypanosoma cruzi "in vitro". Emprego da violeta de genciana na profilaxia da transmissão da moléstia de Chagas por transfusão de sangue. Hospital, Rio de Janeiro, 44:731-44, 1953.

5. PINTO, P. L. S.; AMATO NETO, V.; DUARTE, M. I. S.; COTRIM, J. X.; MOREIRA, A. A. B.; SANT'ANA, E. J.; CAMPOS, R. Estudo experimental sobre possível atividade da violeta de genciana na profilaxia da transmissão da toxoplasmose por transfusão de sangue. Rev. Inst. Med. trop. S. Paulo, 27: 89-94, 1985.

6. SOUZA, H. M. Estudo do metabolismo e viabilidade do sangue fresco e preservado tratado pela violeta de genciana. São Paulo, 1985. [Tese de Doutoramento - Escola Paulista de Medicina].

Recebido para publicação em: 15/4/1987 Reapresentado em: 16/9/1987

Aprovado para publicação em: 17/9/1987 